\title{
Como o esgoto pode retratar o cenário de contaminações pela COVID-19?
}

A COVID-19 caracterizou-se como uma doença desafiadora para a saúde pública no mundo em função da falta de conhecimento acerca do vírus SARS-COV-2, suas formas de contágio, bem como as consequências causadas ao organismo humano. O presente artigo apresenta dados sobre a existência de material genético do novo coronavírus nas fezes de indivíduos com a presença da doença, sendo eles sintomáticos ou assintomáticos. Para isso, foi realizado um levantamento bibliográfico no período de junho até outubro de 2020, nas bases de dados Science Direct, Web of Science, Portal de Periódicos da CAPES, Scielo, PubMed, google acadêmico, além de repositórios de instituições de ensino e pesquisa. No desenvolver da pesquisa foi possível evidenciar as ações de vigilância dos sistemas de esgotamento sanitário nesse momento de pandemia e em ações que percorrem a saúde da coletividade, sendo apresentado o potencial do esgoto como ferramenta epidemiológica no monitoramento da propagação do novo coronavírus e de outras doenças infecciosas. Abordou-se, ainda, o controle do agente patogênico tanto a nível internacional quanto nacional, destacando os fatores que influenciam a quantidade de carga viral no organismo e o potencial infeccioso do vírus encontrado no esgoto.

Palavras-chave: Saúde Pública; Coronavírus; Esgoto; Vigilância epidemiológica.

\section{How can sewage picture the contamination scenario by COVID-19?}

\begin{abstract}
A COVID-19 was characterized as a challenging disease for the public health in the world due to the lack of knowledge about the SARS-COV-2 virus, its forms of contagion, as well as the consequences caused to the human organism. This article presents data on the existence of genetic material of the new coronavirus in the feces of individuals with the presence of the disease, being them symptomatic or asymptomatic. For this, a bibliographic survey was carried out from June to October 2020, in the databases Science Direct, Web of Science, CAPES Periodicals Site, Scielo, PubMed, academic google, besides repositories of teaching and institutional research. In the development of the work, it is possible to put in evidence the surveillance actions of the sanitary exhaustion system in this moment of pandemic, and also, in actions that go through the health of the collectivity. The potential of sewage was presented as an epidemiological tool in monitoring the spread of the new corona virus and other infectious diseases as well. The control of the pathogenic agent was also discussed, both at international and national levels. The factors that influence the amount of viral load in the organism and the infectious potential of the virus found in sewage were presented. Finally, in Brazil the great challenge regarding the monitoring of the new coronavirus using the epidemiology of sewage is the inefficiency of basic sanitation services.
\end{abstract}

Keywords: Public Health; Coronavirus; Sewage; Epidemiological monitoring.

Topic: Epidemiologia e Saúde Ambiental

Reviewed anonymously in the process of blind peer.
Received: 03/03/2021

Approved: 21/03/2021

Halana Tereza Marques de Jesus Ambrosio (it Universidade Federal do Maranhão, Brasil http://lattes.cnpq.br/8636499525099814 http://orcid.org/0000-0003-2359-4545 halanaambrosio@gmail.com

Marcos André Capitulino de Barros Filho (iD) Universidade Federal do Maranhão, Brasil http://lattes.cnpq.br/8824952610047891 http://orcid.org/0000-0003-1827-8724 marcos.capitulino@ufma.br

Referencing this:

AMBROSIO, H. T. M. J.; BARROS FILHO, M. A. C.. Como o esgoto pode retratar o cenário de contaminações pela COVID-19?. Revista lbero Americana de Ciências Ambientais, v.12, n.3, p.145-154, 2021. DOI: http://doi.org/10.6008/CBPC2179-6858.2021.003.0014 


\section{INTRODUÇÃO}

A COVID-19 caracterizou-se como uma doença desafiadora para a saúde pública no mundo, em função da falta de conhecimento acerca do vírus SARS -COV-2, suas formas de contágio, bem como as consequências causadas ao organismo humano. Tais fatores têm impulsionado estudos na procura de investigar as rotas de transmissão e as formas de tratamento para pessoas acometidas pela doença. Desde a gripe espanhola, o mundo não viveu uma crise na saúde tão importante, com impactos significativos e profundos em vários aspectos sociais (YUEN et al., 2020).

Pesquisas e estudos relacionados ao surto mundial de SARS elucidaram que a principal forma de transmissão está relacionada ao meio de contato pessoal próximo, de forma mais específica a exposição de uma pessoa não infectada a gotículas de secreções provenientes do pulmão de uma pessoa infectada (TSANG et al., 2020; LEE et al., 2003; WHO, 2003; CYRANOSKI et al., 2003; POUTANEN et al., 2003; DONNELLY et al., 2003).

O monitoramento de forma rápida e eficaz na propagação de enfermidades é uma ferramenta fundamental na prevenção, no controle e na intervenção. Porém, os sistemas de vigilância possuem limitações ao lidar com o acelerado crescimento populacional, e ainda com o aparecimento de novos microrganismos que causem enfermidades e com o reaparecimento de infecções que antes já estavam controladas (SIMS et al., 2020).

Estudos recentes expuseram a existência de material genético do novo coronavírus nas fezes de indivíduos com a presença da doença, sendo eles sintomáticos ou assintomáticos (WU et al., 2020; XU et al., 2020; ZHANG et al., 2020; SUN et al., 2020) e em amostras de efluentes sanitários (WURTZER et al., 2020; MEDEMA et al., 2020) assinalando novas problemáticas a serem solucionadas pelas instituições governamentais de países e estados.

O surgimento de discussões sobre a transmissão oral-fecal, coloca em evidência as ações de vigilância dos sistemas de esgotamento sanitário nesse momento de pandemia, e, ainda, em ações que percorrem a saúde da coletividade. É importante ressaltar que a OMS (Organização Mundial da Saúde) declarou que esse tipo de disseminação não é uma característica básica da doença.

O estudo de Wu et al. (2020) menciona ainda que pacientes com o novo coronavírus podem expelir o vírus nas fezes por dias que postergam o desaparecimento de todos os sintomas respiratórios. Porém, a constância da doença em águas residuárias ainda não foi concluída.

A partir do que se discutirá neste artigo, tem -se como finalidade apresentar o potencial do esgoto como ferramenta epidemiológica no monitoramento da propagação do novo coronavírus.

\section{METODOLOGIA}

Para obter as informações aqui expostas, foi realizado um levantamento bibliográfico, no período de junho até outubro de 2020, nas bases de dados Science Direct, Web of Science, Portal de Periódicos da CAPES, Scielo, PubMed, google acadêmico, além de repositórios de instituições de ensino e pesquisa. 
A fim de facilitar a busca dos materiais consultados, foram utilizadas estratégias de busca como uso de termos para pesquisa, tais como 'wastewater', 'COVID-19', 'sewage coronavírus', 'epidemiologia esgoto', 'monitoring coronavirus wastewater'. Como o assunto em relação à pandemia é recente, as publicações consultadas para o levantamento bibliográfico são basicamente do ano de 2020. O idioma principal das fontes consultadas foi o inglês e os tipos de documentos baseados foram artigos originais, de revisão, notas técnicas e boletins epidemiológicos.

\section{DISCUSSÃO TEÓRICA}

\section{Uso do esgoto para monitoramento de outras doenças infecciosas}

Castiglioni et al. (2016) apresentou em seu estudo uma estratégia epidemiológica denominada de Epidemiologia do Esgoto, do inglês Wastewater-Based Epidemiology - WBE, que se utiliza de estimativas obtidas da análise de amostras adquiridas por meio de efluentes sanitários para estimar a quantificação de moléculas e metabólitos adulterantes nessas amostras. Na Figura 1, pode-se observar a estrutura da WBE, e de que forma a metodologia se diferencia quando se trata de indivíduos isolados e uma comunidade em geral para descobrimento de patógenos em amostras.
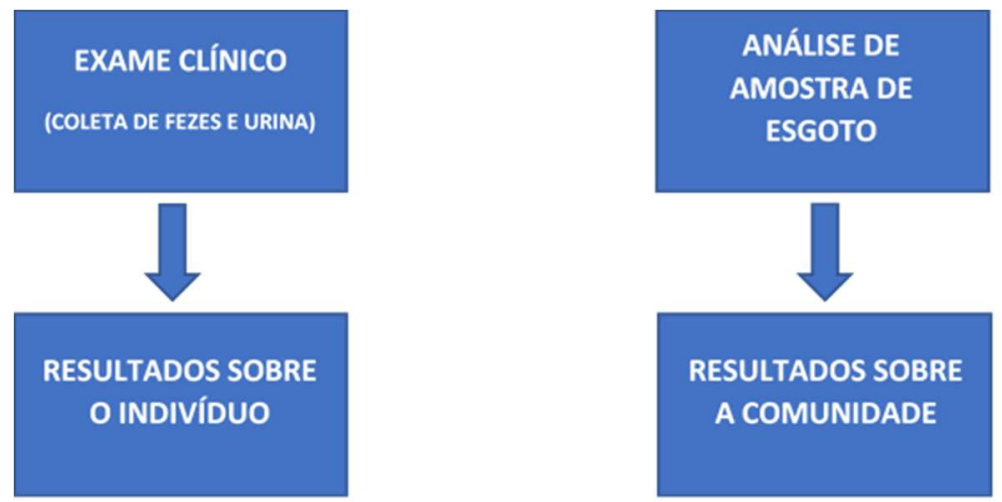

Figura 1: Diferenciação da reposta de análises clínicas comuns e individuais e da epidemiologia do esgoto.

A epidemiologia do esgoto apresenta elevado potencial no que se refere a informações sobre padrões de consumo de entorpecentes, além de servir como parâmetro para medir aspectos socioeconômicos relacionados a saúde pública (JIANG et al., 2020). Em estudo recente, O'Bannon et al. (2020) ajustou a estratégia para identificação da exposição de populações a doenças infecciosas.

Hellmér et al. (2014) investigaram a presença de vírus patógenos em efluentes das cidades de Ryaverket, Gotemburgo e Suécia, a fim de analisar se a presença desses microrganismos poderia ser utilizada como aviso prévio de surtos. O estudo concluiu que os dados encontrados sobre as cepas dos patógenos descobertos no esgoto podem ter uso oficial como identificação de doenças transmissíveis, já que o monitoramento realizado de forma regular pode dar um alerta precoce sobre surtos. A ferramenta estima a carga de infecção de uma comunidade específica, pois quando os vírus são identificados no esgoto, sabe-se que há pessoas infectadas na comunidade e, consequentemente, os vírus estão em circulação na população. Os resultados indicaram que haviam mais pessoas infectadas excretando vírus do que aquelas diagnosticadas com essas infecções durante o período do estudo. 
Em Cingapura foi realizado um estudo que se utilizava de técnicas moleculares, a fim de detectar e caracterizar adenovírus, astro vírus, enterovírus, noro vírus e HAV (Vírus da Hepatite A) humanos em efluentes. O estudo apontou uma elevada predominância (taxa de detecção superior a 70\%) dos vírus no esgoto urbano. Esses valores elevados para os patógenos entéricos no efluente reflete a circulação em alta frequência na população da cidade (AW et al., 2010).

É importante ressaltar que a epidemiologia do esgoto se configura como uma estratégia alternativa, rápida e que já foi utilizada em algumas partes do mundo para estimar a exposição de populações e comunidades à patógenos caracterizados, no geral, por fragmentos de seus genes.

\section{Descobertas reveladas através do monitoramento do esgoto acerca do novo coronavírus e o controle do agente patogênico}

No cenário atual das infecções por coronavírus é possível observar uma subnotificação dos casos, pois os testes usados não estão sendo aplicados a toda a população, apenas aos pacientes acometidos pela COVID-19 com sintomas mais graves.

Hellmér et al. (2014) realizaram em sua pesquisa o monitoramento de amostras de águas residuárias hospitalares, ocorrendo inicialmente a coleta em estações de tratamento de esgoto e em outros pontos determinados no estudo. Nas amostras foram avaliados e quantificados o RNA viral do SARS-COV-2 (coronavírus) através de análises moleculares. Dessa forma, o monitoramento do esgoto pode ser um aliado da vigilância clínica atual, servindo, ainda, como alerta prévio para atenção a contaminação nas cidades pelo coronavírus, assim como na Holanda o método tem sido aplicado para o poliovírus.

No Brasil, uma iniciativa conjunta da Agência Nacional de Águas (ANA, 2020) e do Instituto Nacional de Ciência e Tecnologia em Estações de Tratamento de Esgoto Sustentáveis (INCT ETEs Sustentáveis - UFMG), em parceria com a Companhia de Saneamento de Minas Gerais (Copasa), o Instituto Mineiro de Gestão das Águas (IGAM) e a Secretaria de Estado de Saúde de Minas Gerais (SES), deu origem ao Projeto Monitoramento COVID Esgotos, através do qual é realizada a deteç̧ão e quantificação do novo coronavírus em amostras de esgoto coletadas em diferentes pontos do sistema de esgotamento sanitário das cidades de Belo Horizonte e Contagem. Além disso, os pesquisadores elaboram mapas que indicam a ocorrência do vírus no esgoto das regiões estudadas.

No decorrer do estudo, os pesquisadores pretendem identificar convergências e alterações na ocorrência de infecções virais nas diferentes regiões de análise, a fim de compreender a prevalência e dinâmica na circulação do vírus. O estudo permitirá a realização do mapeamento dos esgotos, indicando áreas com maior incidência de transmissão, o que permitirá direcionar a população quanto as medidas de relaxamento do isolamento social. Além disso, será possível avisar precocemente a comunidade acerca dos riscos de aumento de incidência da COVID-19 de forma regionalizada, embasando a tomada de decisão dos gestores públicos.

A importante contribuição do projeto frente ao cenário de pesquisas e descobertas é que mapeando as concentrações do novo coronavírus nas regiões estudadas, será possível obter um panorama das 
concentrações por região. Os dados auxiliarão as autoridades da área da saúde a inter-relacioná-los às informações obtidas pelo Sistema Único de Saúde (SUS), permitindo um melhor posicionamento a respeito da circulação do vírus.

\section{Experiência internacional}

O estudo de Medema et al. (2020) foi o precursor na determinação do RNA SARS-CoV-2 em esgoto durante o surgimento da pandemia. A pesquisa foi realizada na Holanda, tendo sido coletadas amostras de seis cidades além do aeroporto do país. Os pontos de coleta determinados foram as Estações de Tratamento de Águas Residuárias (ETAR) que atendiam as cidades estudadas, incluindo o aeroporto.

A metodologia da pesquisa se deu coletando quatro séries de amostra, que foram realizadas em fevereiro e março de 2020. A primeira sequência de amostragem ocorreu 3 semanas antes do primeiro caso de COVID-19 ser reconhecido pelo sistema de vigilância em saúde na Holanda, em 27 de fevereiro de 2020. A segunda, terceira e quarta sequências de amostragem foram realizadas após 1, 2 e 4 semanas de epidemia na Holanda, respectivamente.

Após as análises dos dados obtidos a partir de exames laboratoriais, o estudo apresentou que o número cumulativo de casos notificados da COVID-19, relatados em cada uma das cidades atendidas pela ETAR, aumentou em taxas diferentes à medida que a epidemia se espalhava. Foi identificado que a eliminação do agente patogênico nas fezes de pessoas infectadas, continuou por 3 a 4 semanas após o aparecimento dos sintomas. O fato se relacionou diretamente as semanas de coleta das amostras, que apresentaram positividade para a presença do RNA viral nas fezes. Tais informações forneceram evidências concretas de que o RNA do SARS-CoV-2 é detectado no esgoto, e que a vigilância epidemiológica do esgoto pode ser uma ferramenta para monitorar tendências da doença nas cidades.

Na china, a pesquisa de Wu et al. (2020) foi realizada em 74 pessoas hospitalizadas com COVID - 19 no Quinto Hospital Afiliado da Universidade Sun Yat-sen, das quais foram coletadas amostras respiratórias e fecais. As amostras fecais de 33 pacientes apontaram negatividade para a presença do RNA SARS CoV-2, enquanto os esfregaços respiratórios assinalaram positivos por uma média de 16 dias desde o início dos primeiros sintomas. O resultado tanto das amostras fecais quanto respiratórias dos 41 pacientes que restaram, testou positivo para SARS-CoV-2, e permaneceram positivas após novas coletas e análises durante 17 dias para mostras retiradas do trato respiratório e 28 dias para aquelas retiradas das fezes, dias esses contabilizados após o início dos primeiros sintomas, concluindo que por uma média de 11 dias a mais as amostras fecais continuaram positivas em relação as amostras respiratórias.

Analisando os dados obtidos com as duas experiências internacionais relatadas, é possível inferir algumas informações relevantes. Os estudos verificaram correlações entre o número de pessoas infectadas e a carga viral presente no esgoto, podendo concluir que o RNA viral pode estar presente no organismo das pessoas infectadas, mesmo quando não há mais sintomas aparentes. Outra questão importante a ser levantada, é a resistência de fragmentos da carga viral, pois a presença dos microrganismos no esgoto é uma realidade e levanta questionamentos quanto a contaminação pela via oral-fecal. Nenhum estudo comprovou 
esse tipo de contaminação, no entanto, é uma rota que merece atenção já que o Brasil não apresenta boa cobertura do serviço de esgotamento sanitário.

\section{Experiência nacional}

Através do Projeto Monitoramento COVID Esgotos são realizadas análises em laboratório que detectam e quantificam a presença relativa do novo coronavírus no esgoto. As amostras são coletadas em diferentes pontos do sistema de esgotamento sanitário das cidades de Belo Horizonte e Contagem, e os resultados são divulgados na forma de mapas dinâmicos e boletins de medição que possibilitam o acompanhamento da evolução da doença, permitindo melhor entendimento sobre a circulação do novo coronavírus nas regiões pesquisadas.

$\mathrm{Na}$ escolha dos pontos para coleta, foram considerados inúmeros fatores, entre eles o índice de vulnerabilidade da saúde, abrangendo amplo espectro de classes sociais; a presença e acessibilidade à rede coletora de esgoto para coleta das amostras; amostragem de estações de tratamento de esgoto, a fim de avaliar a influência do processo de tratamento na remoção do novo coronavírus, entre outros. Foram escolhidos 24 pontos para coleta, sendo 2 pontos de efluente das principais estações de tratamento das regiões e 22 para coleta de esgoto bruto

O estudo é desenvolvido de maneira regionalizada, identificando a ocorrência do patógeno em áreas que abrangem diferentes níveis sociais e de vulnerabilidade no setor de saúde. Os resultados dos boletins contribuem para se estimar o número de pessoas infectadas, consistindo em uma testagem indireta que inclui os indivíduos sintomáticos e assintomáticos acometidos pela doença. Essa informação é de extrema importância, tendo em vista que a testagem clínica para a presença do vírus só vem sendo feita para uma parcela diminuta da população, o que repercute em um índice elevado de subnotificações de pessoas infectadas.

Foram disponibilizados até setembro de 2020, 15 boletins de acompanhamento da COVID - 19 no esgoto e as semanas foram monitoradas consecutivamente nas sub- bacias do Ribeirão Arrudas e Onça, e os resultados categorizados periodicamente.

Os primeiros boletins ( 1 ao 5 ) trouxeram informações apenas das coletas analisadas nos pontos, os quais mostraram o crescimento dos percentuais de amostras positivas para o coronavírus, com atenção para a sub-bacia do Onça que esteve em crescimento em todas as semanas monitoradas.

A partir do boletim de número 5 , são apresentadas estimativas do quantitativo de pessoas infectadas pelo novo coronavírus, com base nos dados já obtidos pelo monitoramento do esgoto, relacionando aos números de casos confirmados da doença nas regiões estudadas. Portanto, com base em estimativas realizadas, na oitava semana de monitoramento havia cerca de 20.000 pessoas infectadas. $O$ boletim seguinte trouxe um resultado inédito, pois pela primeira vez, em nove semanas de monitoramento, 100\% das amostras testaram positivas na Bacia do Arrudas.

Os resultados obtidos até o boletim de número 15 apontaram as tendências de crescimento, e a partir do 160 as amostras coletadas em um dos nove pontos de pesquisa na bacia do ribeirão do Arrudas 
apontaram duas semanas de declínio para a positividade ao novo coronavírus.

Os pesquisadores já afirmavam redução das curvas de casos confirmados e, possivelmente, da carga viral na população, porém ao serem divulgados os dados do boletim de número 17, no dia 02 de outubro de 2020, ocorreu uma explosão de casos nos pontos de coleta, indicando os picos de infecção e circulação do vírus, pois todas as sub-bacias monitoradas retornaram a apresentar resultados positivos.

Dentro desse quadro, os pesquisadores enfatizam a importância de se manter as medidas de proteção e controle, a fim de reduzir a propagação da doença e evitar o agravamento da pandemia. Apesar das incertezas constantemente relatadas ao longo das publicações, os resultados indicaram tendência de agravamento da pandemia nas regiões, chamando atenção para medidas de controle com vistas a reduzir a disseminação da doença.

Diante disso, é possível afirmar que o método para monitorar o esgoto é viável, desde que se tenha tecnologia adequada e esforços somados de diferentes instituições. Os dados obtidos no projeto mostraram que a tendência de crescimento da doença esteve diretamente relacionada a positividade encontrada nas amostras coletadas nos pontos estudados. Foi possível notar, inclusive, que mesmo com o decrescimento e diminuição dos números de casos notificados, o boletim de número 17 publicado em outubro de 2020 mencionou que os resultados apontaram para cargas ainda elevadas, o que demanda precaução quanto as medidas de controle e combate ao coronavírus.

\section{Fatores que influenciam a quantidade de carga viral no organismo e o potencial infeccioso do vírus encontrado no esgoto}

Um artigo publicado no periódico Journal of General Internal Medicine, dos autores Gandhi et al. (2020), sugere que dependendo da quantidade da carga viral presente no organismo do indivíduo infectado os sintomas da COVID - 19 poderão ser mais brandos ou mais graves. A carga viral é definida como o quantitativo de cópias virais presentes em certos fluidos ou secreções, e a partir do momento que a pessoa é infectada o vírus inicia sua replicação, sendo possível a detecção em exames.

A teoria abordada na pesquisa baseia-se na hipótese de que reduzindo o inócuo viral (dose do vírus) ao qual o indivíduo é exposto, levar-se-ia a taxas mais leves ou assintomáticas da COVID-19. O mecanismo proposto para tal efeito é o uso das máscaras que filtram a maior parte das partículas que entram em contato com ela. Analisando a perspectiva adotada no estudo, eleva-se ao nível máximo a importância do uso da máscara durante a pandemia do novo coronavírus, e como a carga viral que a pessoa recebe influência nos sintomas apresentados, pois as máscaras não barram de maneira total a passagem do material viral. No entanto, quando esse quantitativo ao entrar no corpo é reduzido, o organismo age mais rápido no combate, resultando em sintomas mais brandos e sem complicações.

Em relação ao vírus encontrado no esgoto, excretado pelos indivíduos já infectados, fica a seguinte pergunta: qual o potencial infeccioso?. Na pesquisa de Sun et al. (2020) um paciente chinês foi internado em um hospital de referência no país, em janeiro de 2020, com sintomas graves da nova doença. Com a piora do quadro do indivíduo, foram realizados testes de urina, que apresentaram positividade para o RNA da SARS- 
COV-2. A pesquisa constatou que a quantidade de carga viral era detectável, no entanto baixa, sendo assim o estudo concluiu que a possibilidade de isolar o RNA viral na urina do paciente era um ponto de atenção para a contaminação pela transmissão fecal/oral.

Wang et al. (2020) investigou a bio distribuição de RNA viral em diferentes tecidos de pacientes internados com o novo coronavírus baseados nos sintomas e radiologia, quando os exames testavam positivo para a doença. As amostras eram coletadas do sangue, expectoração, fezes, urina e das vias nasais, e nos resultados mais expressivos encontrados, o SARS-COV-2 foi observado ativo em duas amostras de pacientes. Os autores chamam atenção para as implicações na descoberta de carga viral ativa nas fezes, implicando em uma possível transmissão por tal via.

Os dados apresentados acima, assim como outros apresentados ao longo deste artigo, permitem afirmar que o novo coronavírus foi encontrado em amostras de esgoto, assim como nas fezes de alguns pacientes. Destaca-se, que o potencial contaminante do vírus nas fezes não foi calculado, sendo, assim, a presença não é consequência direta de infeccionar outras pessoas. A certeza obtida é que o coronavírus é transmitido pelo contato das pessoas com aerossóis contaminados com saliva e outras secreções do trato respiratório. No entanto, com esses resultados de detecção de alta carga viral em fezes de infectados, é uma nova rota para investigação das informações e implicações que trazem à saúde pública.

Monitorar o esgoto para fins ambientais e populacionais deve ser alvo de estudos mais intensos, já que diversos motivos justificam seu uso, tais como a identificação das curvas de contágio e disseminação, a fim de conhecer as comunidades infectadas e analisar de que forma os portadores sem sintomas contribuem na disseminação viral e o uso da metodologia de análise do esgoto para possibilitar a criação de um sistema de alerta para presença de cargas virais elevadas, podendo, assim, criar formas de conscientizar a população por meio de campanhas.

\section{Desafios}

Em um cenário de pandemia a disseminação catastrófica pode ser restringida ou limitada com o uso de testes suficientes na população. Nesse contexto, Gronvall et al. (2020) relataram que essa aplicação maciça é prejudicada pela falta dos testes, além da deficiência em diagnósticos obtidos clinicamente que detectam infecções atuais ou anteriores.

Nessa perspectiva, de acordo com Hasell et al. (2020) a forma com que os testes estão sendo aplicados necessita de expansão ininterrupta, com o intuito de que a porcentagem da população testada seja alcançada em um quantitativo suficiente. Esse quantitativo faz menção aos testes concluídos que revelaram casos positivos confirmados, tornando-se um indicador mais eficaz e direto da expansão da infecção na sociedade. Quando o método utilizado é por amostragem de testes, a tendência é se obter uma elevada incidência na infecção, sendo é importante a intensificação nas testagens até que a proporção de testes positivos aumente significativamente, indicando sucesso nas medidas de controle.

Quanto ao método da epidemiologia do esgoto, a diluição elevada de biomarcadores (que evidenciam a presença de patógenos) é uma adversidade ao uso, pois a água residual, por si só, oferece um 
ambiente complexo de se obter dados nas amostras analisadas. Outro aspecto a ser evidenciado é a quantidade de informações obtidas ao se analisar o esgoto, visto que a extração de informações precisas na análise torna-se dificultada e um ensaio posterior não é possível. Dúvidas no quantitativo da população também representam entraves para a vigilância de doenças infecciosas em águas residuárias, uma vez que a presença de turistas ou passageiros em uma área de captação inviabiliza o monitoramento do aparecimento real de uma infecção na comunidade estudada (DAUGHTON, 2012).

Outro ponto que levanta questionamentos é como monitorar o esgoto em regiões que não possuem atendimento de coleta pública. Uma solução viável seria monitorar o córrego ou ribeirão que recebe os resíduos. Porém, tal linha de pesquisa é muito mais complicada, pois ao se considerar o período de pluviosidade, muito material é carregado se diluindo na água, tornando a amostra ainda mais inviável. Outro meio é mudar o monitoramento regionalizado para monitoramento em locais públicos, onde há uma concentração mais elevada de pessoas, tomando como base de coleta de dados, por exemplo, os banheiros públicos.

No Brasil, o grande desafio em relação ao monitoramento do novo coronavírus usando a epidemiologia do esgoto é a baixa cobertura dos serviços de saneamento básico. Uma realidade no país é que milhões de pessoas não possuem acesso à rede de esgoto, estando expostas à péssimas condições sanitárias. O diagnóstico do Sistema Nacional de Informações sobre Saneamento (SNIS), realizado a partir das informações e indicadores dos prestadores de serviços que participaram da coleta de dados do ano de 2019, tendo como ano de referência 2018, revelou que 60,9\% da população recebe o atendimento por redes coletoras de esgoto, dando destaque a região sudeste que possui o maior percentual do país (83.3\%).

\section{CONCLUSÕES}

Estudos demonstraram a possível contaminação pelo esgoto a partir do SARS-COV-2. Tal fato aponta para que sejam adotadas medidas de ação para a COVID -19 utilizando a epidemiologia do esgoto.

Com base nas experiências nacionais e internacionais é possível afirmar que a epidemiologia do esgoto consiste em ferramenta capaz de diagnosticar e mapear doenças, permitindo a identificação de curvas de contágio e disseminação, o que possibilita o desenvolvimento de um sistema de alerta precoce de surtos para a comunidade monitorada. O sucesso do uso da ferramenta, portanto, depende de uma boa cobertura por redes coletoras de esgoto, bem como de um efetivo controle dos dados de monitoramento por parte das companhias de saneamento.

\section{REFERÊNCIAS}

ANA. Agência Nacional de Águas e Saneamento Básico. Monitoramento COVID esgotos: Boletins de

Acompanhamento, Semanas Epidemiológicas 16 à 39 abr/out.2020. Brasília: ANA, 2020.

AW, T.; GIN, K.-H.. Environmental surveillance and molecular characterization of human enteric viruses in tropical urban wastewaters. Journal of Applied Microbiology, v.109, p.716 730, 2010. DOI: http://doi.org/10.1111/j.1365-2672.2010. 04701.x
CASTIGLIONI, S.; BORSOTTI, A.; RIVA, F.; ZUCCATO, E.. Illicit drug consumption estimated by wastewater analysis in different districts of Milan: A case study', Drug and Alcohol. 2016.

CYRANOSKI, D.; ABBOTT, A.. Apartment complex holds clues to pandemic potential of SARS. Nature, v.423, p.3-4, 2003. DOI: https://doi.org/10.1038/423003a. 
DAUGHTON, C. G.. Usando biomarcadores em esgotos para monitorar a saúde humana em toda a comunidade: isoprostanos como protótipo conceitual. Sci. Total Environ., v.424, p.16-38, 2012.

DONNELLY, C. A.; GHANI, A. C.; LEUNG, G. M.; HEDLEY, A. J.; FRASER, C.; RILEY, S.; ABU-RADDADA L. J.; HO, L. M.; THACHB, T. Q.; CHAU, P.; CHAN, K. P.; LAM, T.-H.; TSE, L.Y.; TSANG, T.; LIU, S.-H.; KONG, J. H. B.; LAUE, E. M. C.; FERGUSON, N. M.; ANDERSON, R. M.. Epidemiological determinants of spread of causal agent of severe acute respiratory syndrome in Hong Kong. Lancet, v.361, n.9371, p.1761-1766, 2003. DOI: http://doi.org/10.1016/S01406736(03)13410-1

GANDHI, M.; BEYRER, C.; GOOSBY, E.. Masks Do More Than Protect Others During COVID-19: Reducing the Inoculum of SARS-CoV-2 to Protect the Wearer. J. Gen. Intern. Med., v.35, n.10, p.3063-3066, 2020. DOI: https://doi.org/10.1007/s11606-020-06067-8.

GRONVALL, G.. Developing a National Strategy for Serology (Antibody Testing) in the United States. The Johns Hopkins Center for Health Security, 2020.

HASELL, J.; ORTIZ-OSPINA, E.; MATHIEU, E.; RITCHIE, H.; BELTEKIAN, D.; ROSER, M.. To understand the global pandemic, we need global testing: the Our World in Data COVID-19 testing dataset Our World in Data 2020. 2020.

HELLMÉR, M.; PAXÉUS, N.; MAGNIUS, L.; ENACHE, L.; ARNHOLM, B.; JOHANSSON, A.; BERGSTRÖM, T.; NORDER, $\mathrm{H}$.. Detection of pathogenic viruses in sewage provided early warnings of hepatitis a virus and norovirus outbreaks. Appl. Environ. Microbiol., v.80, n.21, p.6771-6781, 2014. DOI: http://doi.org/10.1128/AEM.01981-14

JIANG, G.; LI, X.. A new paradigm for environmental chemistry and toxicology: from concepts to insights. Singapore: Springer Singapore, 2020.

LEE, N.; HUI, D.; WU, A.; CHAN, P.; CAMERON, P.; JOYNT, G. M.; AHUJA, A.; YUNG, M. Y.; LEUNG, C. B.; TO, K. F.; LUI, S. F.; SZETO, C. C.; CHUNG, S.; SUNG, J. J. Y.. A major outbreak of severe acute respiratory syndrome in Hong Kong. NEJM, v.348, p.1986-1994, 2003. DOI: http://doi.org/10.1056/NEJMoa030685

MEDEMA, G.; HEIJNEN, L.; ELSINGA, G.; ITALIAANDER, R.; BROUWER, A.. Presence of sars-coronavirus-2 rna in sewage and correlation with reported covid-19 prevalence in the early stage of the epidemic in the netherlands.

Environmental Science \& Technology Letters, v.7, n.7, p.511-516, 2020. DOI:

https://doi.org/10.1021/acs.estlett.0c00357

O'BANNON, D.. In Women in water quality: investigations by prominent female engineers. Springer International Publishing, 2020.

POUTANEN, S. M.; LOW, D. E.; HENRY, B.; FINKELSTEIN, S.; ROSE, D.; GREE, K.; TELLIER, R. N. R.; DRAKER, R.; ADACHI, D.; AYERS, M.; CHAN, A. K.; SKOWRONSKI, D. M.; SALIT, I.; SIMOR, A. E.; SLUTSKY, A. S.; DOYLE, P. W.; KRAJDEN, M.;
PETRIC, M.; BRUNHAM, R. C.; CGEER, A. J. M.. Identification of severe acute respiratory syndrome in Canada. NEJM, v.348, p.1995-2005, 2003. DOI: http://doi.org/10.1056/NEJMoa030634

SIMS, N.; HORDERN, B. K.. Future perspectives of wastewater-based epidemiology: monitoring infectious disease spread and resistance to the community level. Environment International, v.139, 2020. DOI: https://doi.org/10.1016/i.envint.2020.105689.

SUN, J.; ZHU, A.; LI, H.; ZHENG, K.; ZHUANG, Z.; CHEN, Z.; SHI, Y.; ZHANG, Z.; CHEN, S.-B.; LIU, X.; DAI, J.; LI, X.; HUANG, S.; HUANG, X.; LOU, L.; WEN, L.; ZHOU, J.; LI, Y.; WANG, Y.; ZHANG, L.; ZHANG, Y.; LI, F.; FENG, L.; CHEN, X.; ZHONG, N.; YANG, Z.; HUANG, J.; ZHAO, J.; LI, Y.-M.. Isolation of Infectious SARS-CoV-2 from Urine of a COVID-19 Patient. Emerg Microbes Infect., v.28, n.1, p.991-993, 2020. DOI: http://doi.org/10.1080/22221751.2020.1760144

TSANG, K. W.; HO, P. L.; OOI, G. C.; YEE, W. K.; WANG, T.; MOIRA, C. Y.; LAM, W. K.; SETO, W. K.; YAM, L. Y.; WANG, W.; XU, Y.; GAO, R.. Detection of SARS-CoV-2 in Different Types of Clinical Specimens. JAMA, v.323, n.18, p.1843-1844, 2020. DOI:

http://doi.org/10.1001/jama.2020.3786

WHO. World Health Organization. Amoy Gardens Investigation Findings Make Public. WHO, 2003.

WU, Y.; GUO, C.; TANG, L.; HONG, Z.; ZHOU, J.; DONG, X.; YIN, H.; XIAO, Q.; TANG, Y.; QU, X.; KUANG, L.; FANG, X.; MISHRA, N.; LU, J.; SHAN, H.;IANG, G. HUANG, $X$ Prolonged presence of SARS-CoV-2 viral RNA in faecal samples. Lancet Gastroenterol Hepatol., v.5, n.5, p.434-435, 2020. DOI: http://doi.org/10.1016/S2468-1253(20)30083-2

WURTZER, S.; MARECHAL, V.; MOUCHEL, J.-M.; MADAY, Y.; TEYSSOU, R.; RICHARD, E.; ALMAYRAC, J. L.; MOULIN, L. Time course quantitative detection of SARS-CoV-2 in Parisian wastewaters correlates with COVID-19 confirmed cases. MedRxiv, 2020. DOI: http://doi.org/10.1101/2020.04.12.20062679

XU, Y.; LI, X.; ZHU, B.; LIANG, H.; FANG, C.; GONG, Y.; GUO, Q.; SUN, X.; ZHAO, D.; SHEN, J.; ZHANG, H.; LIU, H.; XIA, H.; TANG, J.; ZHANG, K.; GONG, S.. Characteristics of pediatric SARS-CoV-2 infection and potential evidence for persistent fecal viral shedding. Nat. Med., v.26, n.4, p.502-505, 2020. DOI: https://doi.org/10.1038/s41591-020-0817-4

YUEN, K. S.; YE, Z. W.; FUNG, S. Y.; CHAN, C. P.; JIN, D. Y. SARS-CoV-2 and COVID-19: The most important research questions. Cell Biosci., v.10, n.40, 2020. DOI: https://doi.org/10.1186/s13578-020-00404-4

ZHANG, Y.; CHEN, C.; ZHU, S.; SHU, C.; WANG, D.; SONG, J.; SONG, Y.; ZHEN, W.; FENG, Z.; WU, G.; XU, J.; XU, W.. Notes from the Field: Isolation of 2019-nCoV from a Stool Specimen of a Laboratory-Confirmed Case of the Coronavirus Disease 2019 (COVID-19). China CDC Weekly, v.2, n.8, p.123-124, 2020. DOI: http://doi.org/10.46234/ccdcw2020.033

A CBPC - Companhia Brasileira de Produção Científica (CNPJ: 11.221.422/0001-03) detém os direitos materiais desta publicação. Os direitos referem-se à publicação do trabalho em qualquer parte do mundo, incluindo os direitos às renovações, expansões e disseminações da contribuição, bem como outros direitos subsidiários. Todos os trabalhos publicados eletronicamente poderão posteriormente ser publicados em coletâneas impressas sob coordenação da Sustenere Publishing, da Companhia Brasileira de Produção Científica e seus parceiros autorizados. Os (as) autores (as) preservam os direitos autorais, mas não têm permissão para a publicação da contribuição em outro meio, impresso ou digital, em português ou em tradução. 